\title{
Long-term impact of the 70-gene signature on breast cancer outcome
}

\author{
C. A. Drukker $\cdot$ H. van Tinteren $\cdot$ M. K. Schmidt . \\ E. J. Th. Rutgers $\cdot$ R. Bernards $\cdot$ M. J. van de Vijver • \\ L. J. van't Veer
}

Received: 23 December 2013/Accepted: 29 December 2013/Published online: 21 January 2014

(C) The Author(s) 2014. This article is published with open access at Springerlink.com

\begin{abstract}
Several studies have validated the prognostic value of the 70-gene prognosis signature (MammaPrint ${ }^{\mathrm{R}}$ ), but long-term outcome prediction of these patients has not been previously reported. The follow-up of the consecutively treated cohort of 295 patients ( $<53$ years) with invasive breast cancer (T1-2N0-1M0; $n=151 \mathrm{~N} 0, n=144 \mathrm{~N} 1$ ) diagnosed between 1984 and 1995, in which the 70-gene signature was previously validated, was updated. The median follow-up for this series is now extended to 18.5 years. A significant difference is seen in long-term distant metastasisfree survival (DMFS) for the patients with a low- and a highrisk 70 -gene signature (DMFS $p<0.0001$ ), as well as
\end{abstract}

Electronic supplementary material The online version of this article (doi:10.1007/s10549-013-2831-4) contains supplementary material, which is available to authorized users.

\section{A. Drukker · E. J. Th. Rutgers}

Department of Surgical Oncology, Netherlands Cancer Institute, Plesmanlaan 121, 1066 CX Amsterdam, The Netherlands

\section{H. van Tinteren}

Department of Biometrics, Netherlands Cancer Institute,

Plesmanlaan 121, 1066 CX Amsterdam, The Netherlands

\section{K. Schmidt}

Division of Psychosocial Research and Epidemiology, Department of Molecular Pathology, Netherlands Cancer Institute, Plesmanlaan 121, 1066 CX Amsterdam, The Netherlands

R. Bernards

Department of Molecular Carcinogenesis, Netherlands Cancer Institute, Plesmanlaan 121, 1066 CX Amsterdam, The

Netherlands separately for node-negative (DMFS $p<0.0001$ ) and nodepositive patients (DMFS $p=0.0004$ ). The 25-year hazard ratios (HRs) for all patients for DMFS and OS were 3.1 (95\% CI 2.02-4.86) and 2.9 (95\% CI 1.90-4.28), respectively. The HRs for DMFS and OS were largest in the first 5 years after diagnosis: 9.6 (95\% CI 4.2-22.1) and 11.3 (95\% CI 3.5-36.4), respectively. The 25-year HRs in the subgroup of node-negative patients for DMFS and OS were 4.57 (95\% CI 2.31-9.04) and 4.73 (95\% CI 2.46-9.07), respectively, and for node-positive patients for DMFS and OS were 2.24 (95\% CI 1.25-4.00) and 1.83 (95\% CI 1.07-3.11), respectively. The 70-gene signature remains prognostic at longer follow-up in patients $<53$ years of age with stage I and II breast cancer. The 70-gene signature's strongest prognostic power is seen in the first 5 years after diagnosis.

\section{J. van de Vijver}

Department of Pathology, Netherlands Cancer Institute,

Plesmanlaan 121, 1066 CX Amsterdam, The Netherlands

M. J. van de Vijver

Department of Pathology, Academic Medical Center,

Meibergdreef 9, 1105 AZ Amsterdam, The Netherlands

\section{J. van't Veer $(\square)$}

Department of Laboratory Medicine, Helen Diller Family Comprehensive Cancer Center, University of California, San Francisco, 2340 Sutter Street, San Francisco, CA 94115, USA e-mail: vantveerL@cc.ucsf.edu

\section{J. van't Veer}

Department of Molecular Pathology, Netherlands Cancer Institute, Plesmanlaan 121, 1066 CX Amsterdam, The Netherlands

R. Bernards · L. J. van't Veer

Agendia Inc., Sciencepark 406, 1098 XH Amsterdam, The

Netherlands 
Keywords Breast cancer - Risk prediction - Gene signature $\cdot 70$-gene signature

\section{Introduction}

Gene-expression signatures, such as the 70-gene signature $\left(\right.$ MammaPrint $^{\mathrm{R}}$ ), were developed to assess the risk of distant recurrence in the first 5 years after diagnosis to predict outcome of breast cancer patients [1]. The 70-gene signature was extensively validated in several retrospective studies [2-4]. The test was mainly validated in systemically untreated patients with estrogen-receptor (ER) positive and negative invasive breast cancer, $<55$ or 60 years, with no axillary nodal involvement. Subsequently, multiple studies validated this signature for additional subgroups such as patients up to 70 years of age, postmenopausal patients, patients with up to three positive lymph nodes and patients with human epidermal growth factor receptor 2 (HER2)positive disease [5-7]. More recently, the first prospective data on the 70-gene signature were published showing an excellent overall survival for patients with a low risk for recurrence estimation by the 70-gene signature. Even when these low-risk patients did not receive adjuvant chemotherapy, despite 'high risk' clinicopathological factors, they had a 5-year distant recurrence-free interval of $100 \%$ [8].

In studies on the prognostic value of the 70-gene signature published so far, the median follow-up was between 5 and 13.6 years. To our knowledge, no data on long-term survival of patients for whom data from a gene signature, such as the 70-gene signature, OncotypeDx recurrence score or PAM50, are available have been published $[9,10]$. We therefore set out to update the follow-up of the previously published 70 -gene signature consecutive 295 patient cohort, as published by van de Vijver et al. in 2002, to investigate the long-term outcome of breast cancer patients and to evaluate the effect of the 70-gene signature after longer follow-up [4].

\section{Patients and methods}

\section{NKI 295}

Follow-up was updated until September 2013 for a cohort of 295 consecutive patients diagnosed with primary breast cancer. Study design, patient eligibility and study logistics of the study have been described before [4]. In short, all patients were female, younger than 53 years with histologically proven, operable, invasive breast cancer (T12N0-1M0). All were diagnosed at the Netherlands Cancer Institute between 1984 and 1995. 151 of the 295 patients had node-negative disease; 144 patients had node-positive disease. All patients were primarily treated with breastconserving surgery or mastectomy. Adjuvant treatment consisted of radiotherapy, chemotherapy and/or endocrine therapy as indicated by guidelines used at the time of treatment.

\section{0-gene signature}

For all patients included in these analyses, a 70-gene signature result was available. Frozen tumor samples from each patient were processed at the Netherlands Cancer Institute and Rosetta Inpharmatics for RNA isolation, amplification and labeling as described elsewhere [1, 4, 11]. Tumors were classified as a 70-gene signature low or high risk at the time of the initial studies. Low risk was defined as an index score greater than 0.4. High risk was defined as an index score lower than $0.4[1,11]$.

\section{Statistical analysis}

For this analysis, we estimated overall survival (OS) and distant metastasis-free survival (DMFS). DMFS was defined as time from diagnosis to distant metastasis as first event. Data on all other patients were censored on the last date of follow-up, in the event of a second primary tumor including contralateral breast cancer, in case of death from any cause other than breast cancer, or if there was a localregional recurrence of the disease. In case a local-regional recurrence was followed by distant metastasis within 6 months, the event of distant metastasis was included in the analysis. Survival curves were constructed using the Kaplan-Meier method and compared using the log-rank test. Competing risk analyses were performed to adjust for patients having a type of event (for example death due to another cause than breast cancer) that makes them unable to develop the event of interest. The hazard ratios (HRs) of the 70-gene signature were calculated for the full follow-up as well as per 5-year intervals. A significant finding was defined as a $p$ value below 0.05 . Analyses were performed using SAS version 9.2 and $\mathrm{R}$ version 2.14.0.

\section{Results}

NKI 295: patient and tumor characteristics

Patient characteristics are described in Supplementary Table 1 [4]. Of the 295 patients, 115 patients had a low-risk 70 -gene signature and 180 had a high-risk 70 -gene signature. Patients with a low-risk 70-gene signature were more often of older age and had more often smaller estrogen-receptor (ER)-positive tumors with lower grade. No significant difference between patients with low- and high-risk 70-gene 


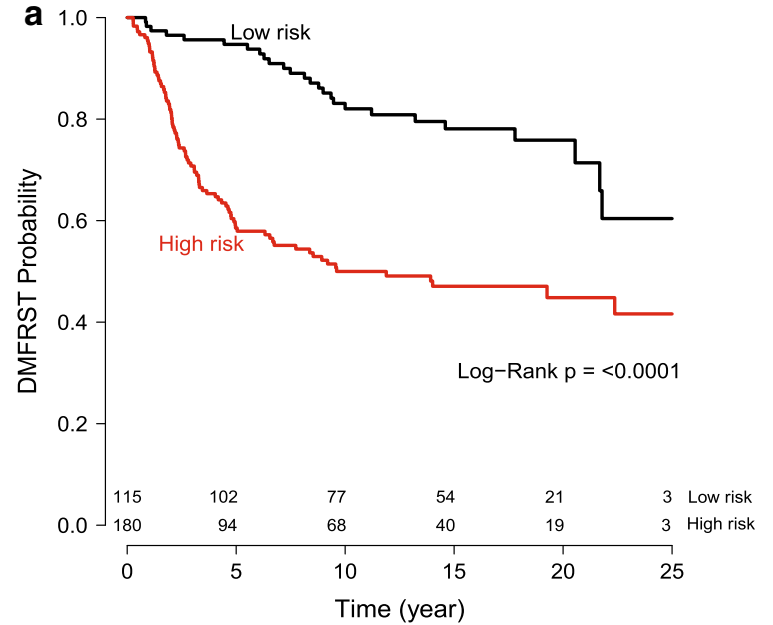

DMFS All patients

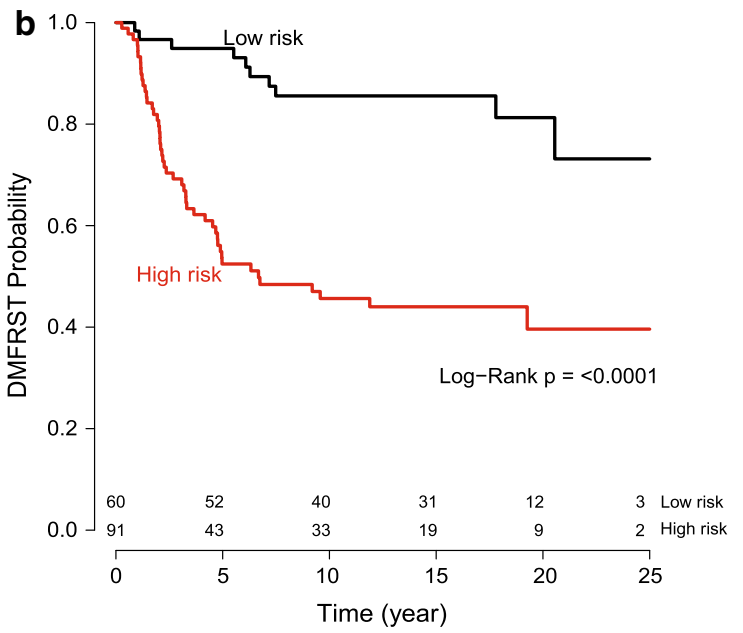

DMFS Node-negative patients

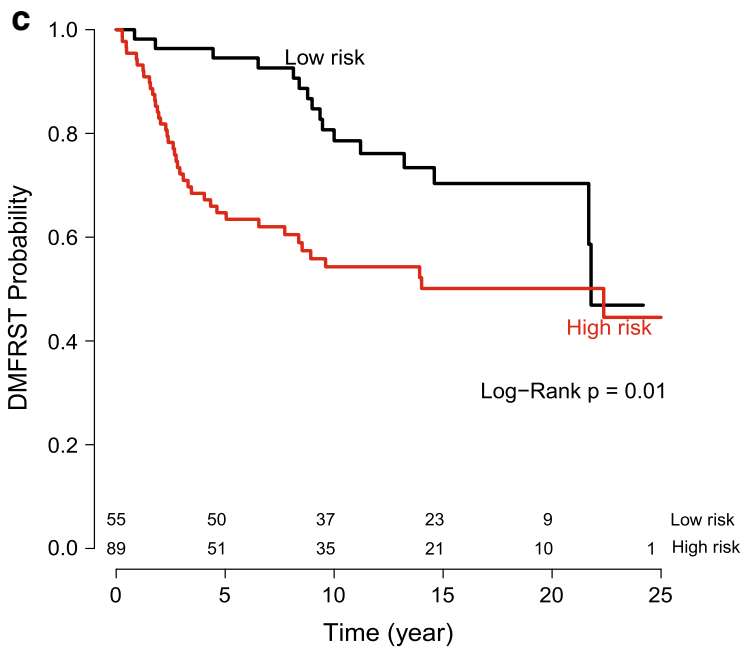

DMFS Node-positive patients

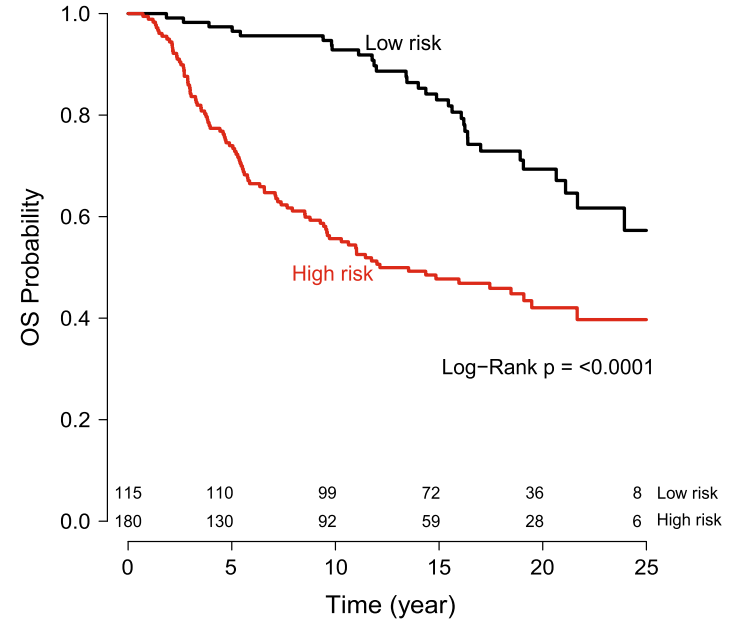

OS All patients

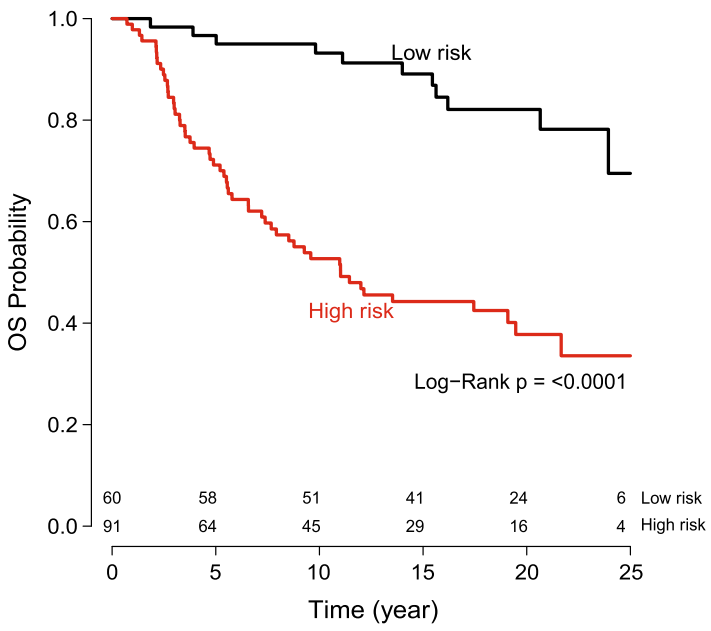

OS Node-negative patients

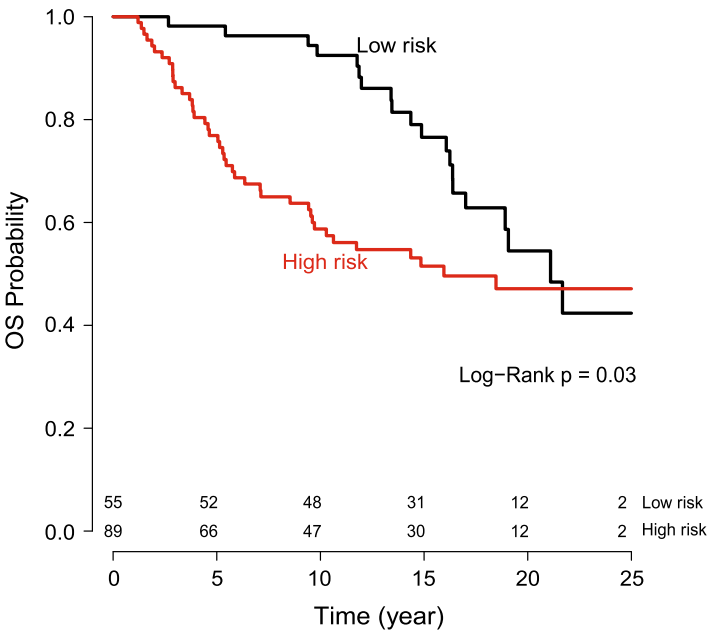

OS Node-positive patients

Fig. 1 Overall survival (OS) and distant metastasis-free survival (DMFS) for all patients and stratified by nodal status 
signature was seen for number of positive nodes, vascular invasion and treatment (type of surgery, adjuvant chemotherapy nor adjuvant endocrine therapy). Thirty-seven percent of the patients received adjuvant chemotherapy, and $14 \%$ received adjuvant endocrine therapy. After a median follow-up of 18.5 years, 121 patients developed distant metastasis as first event. One hundred and twenty-seven patients have died, of whom 114 died due to breast cancer.

Long-term prognostic value of the 70-gene signature

Figure 1 shows DMFS and OS for the entire cohort (1A), and separately for node-negative (1B) and node-positive patients (1C). The Kaplan-Meier curves showed a significant absolute difference in DMFS and OS at 25 years between the patients with a low-risk 70-gene signature (60.4 and $57.3 \%$ respectively) and the patients with a high-risk 70-gene signature (41.6 and $44.5 \%$ respectively; $p<0.0001$ for both OS and DMFS). This significant difference was observed for node-negative $(p<0.0001$ for both OS and DMFS) as well as node-positive patients ( $p=0.03$ for OS and $p=0.0004$ for DMFS). Conditional survival probabilities for all patients and both subgroups for 5, 10, 15, 20 and 25 years are summarized in Table 1. The 25-year HRs for all patients for DMFS and OS were 3.1 (95\% CI 2.02-4.86) and 2.9 (95\% CI 1.90-4.28), respectively. The HR for DMFS in the first 5 years after diagnosis was 9.6 (95\% CI 4.2-22.1) and $11.3(95 \% \mathrm{CI}$ 3.5-36.4) for OS. After 5 years, the effect of the 70-gene signature on DMFS diminished, while the effect on OS from years 5 to 10 after diagnosis was still very significant with a HR 6.1 (95\% CI 2.4-15.6). After 15 years, the effect of the 70-gene signature on OS slowly diminished

Table 2 Hazard ratios for the 70-gene signature for OS and DMFS

\begin{tabular}{|c|c|c|c|c|}
\hline HR & $\begin{array}{l}\text { At risk } \\
95 \% \\
\text { CI }\end{array}$ & & & Events \\
\hline \multicolumn{5}{|c|}{$D M F S$ (years) } \\
\hline $0-25$ & 295 & 111 & 3.1 & $2.02-4.86$ \\
\hline $0-5$ & 295 & 74 & 9.6 & $4.2-22.1$ \\
\hline $5-10$ & 196 & 23 & 1.1 & $0.5-2.5$ \\
\hline $10-15$ & 145 & 6 & 1.2 & $0.2-6.0$ \\
\hline $15-20$ & 94 & 2 & 1.1 & $0.1-17.9$ \\
\hline $20-25$ & 40 & 6 & 0.3 & $0-2.9$ \\
\hline \multicolumn{5}{|c|}{ OS (years) } \\
\hline $0-25$ & 295 & 127 & 2.9 & $1.9-4.28$ \\
\hline $0-5$ & 295 & 49 & 11.3 & $3.5-36.4$ \\
\hline $5-10$ & 240 & 36 & 6.1 & $2.4-15.6$ \\
\hline $10-15$ & 191 & 21 & 1.5 & $0.6-3.5$ \\
\hline $15-20$ & 131 & 15 & 0.6 & $0.2-1.7$ \\
\hline $20-25$ & 64 & 6 & 0.2 & $0-2.1$ \\
\hline
\end{tabular}

Table 1 Distant metastasis-free survival (DMFS) and overall survival (OS) probabilities for all patients and stratified by nodal status

\begin{tabular}{|c|c|c|c|c|c|c|}
\hline Group & No. of patients & 5 years & 10 years & 15 years & 20 years & 25 years \\
\hline \multicolumn{7}{|c|}{ DMFS $(95 \% C I)$} \\
\hline All patients & 295 & & & & & \\
\hline Low risk & 115 & 94.7 (90.7-98.9) & $82.0(75-89.7)$ & $78.1(70.3-86.8)$ & $75.9(67.3-85.5)$ & $60.4(45.3-80.5)$ \\
\hline High risk & 180 & $58.5(51.6-66.4)$ & $50.0(42.8-58.4)$ & $47.1(39.7-55.8)$ & $44.8(36.9-54.5)$ & $41.6(32.6-53.1)$ \\
\hline Node-negative & 151 & & & & & \\
\hline Low risk & 60 & $94.9(89.5-100)$ & $85.6(76.8-95.4)$ & 85.6 (76.8-95.4) & $81.3(70.1-94.3)$ & $73.2(56.7-94.3)$ \\
\hline High risk & 91 & $52.4(42.8-64.2)$ & $45.6(36.0-57.8)$ & $44.0(34.4-56.3)$ & $39.6(28.7-54.6)$ & $39.6(28.7-54.6)$ \\
\hline Node-positive & 144 & & & & & \\
\hline Low risk & 55 & $94.5(88.7-100)$ & $78.6(68.1-90.7)$ & $70.3(58.1-85.1)$ & $70.3(58.1-85.1)$ & No pt at risk \\
\hline High risk & 89 & $64.7(55.3-75.8)$ & $54.3(44.2-66.6)$ & $50.1(39.7-63.3)$ & $50.1(39.7-63.3)$ & $44.5(32.1-61.8)$ \\
\hline \multicolumn{7}{|l|}{ OS $(95 \% C I)$} \\
\hline All patients & 295 & & & & & \\
\hline Low risk & 115 & $97.4(94.5-100)$ & $92.8(88.2-97.8)$ & $83.0(75.9-90.8)$ & $69.4(60-80.2)$ & $57.3(44.8-73.2)$ \\
\hline High risk & 180 & $74.0(67.8-80.7)$ & $55.7(48.7-63.6)$ & $47.7(70.7-56)$ & $42.0(34.6-51.1)$ & $39.7(31.7-49.8)$ \\
\hline Node-negative & 151 & & & & & \\
\hline Low risk & 60 & $96.7(92.2-100)$ & $93.2(87-99.9)$ & $89.1(81.2-97.8)$ & 82.1 (72.0-93.6) & $69.5(52.3-92.2)$ \\
\hline High risk & 91 & $71.1(62.4-81.1)$ & $52.7(43.2-64.2)$ & $44.3(34.9-56.1)$ & $37.8(28.0-50.9)$ & $33.6(23.0-49)$ \\
\hline Node-positive & 144 & & & & & \\
\hline Low risk & 55 & $98.2(94.7-100)$ & 92.5 (85.7-99.9) & $76.6(65.2-89.9)$ & $54.5(40-74.2)$ & $42.2(26.6-67.5)$ \\
\hline High risk & 89 & $76.9(68.5-86.3)$ & $58.7(49.1-70.3)$ & $51.1(41.6-63.8)$ & $47.1(36.8-60.3)$ & $47.1(36.8-60.3)$ \\
\hline
\end{tabular}


70-gene signature low risk

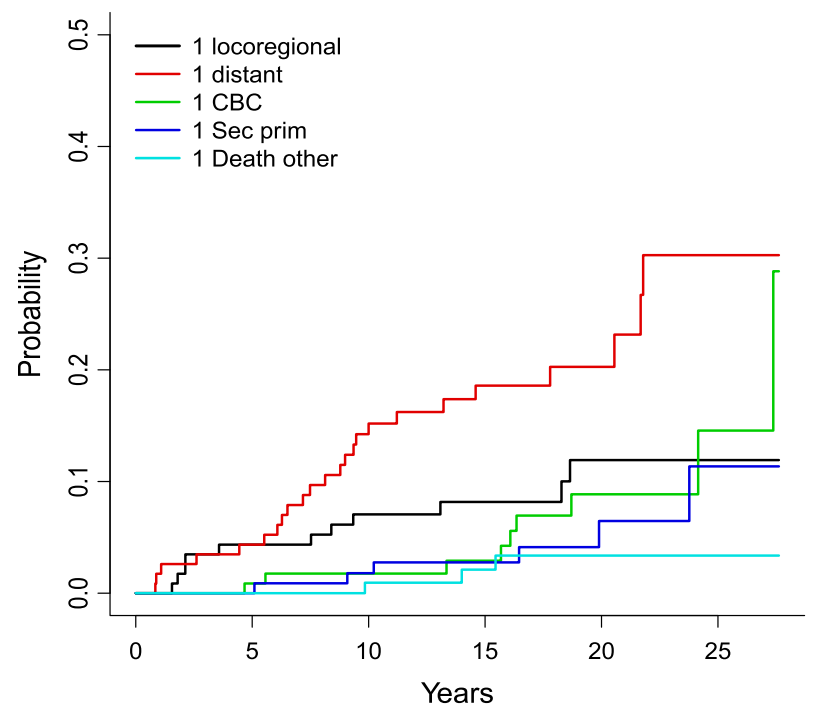

Fig. 2 Competing risk analysis

(Table 2). The 25-year HRs for node-negative patients for DMFS and OS were 4.57 (95\% CI 2.31-9.04) and 4.73 (95 \% CI 2.46-9.07), respectively. The 25-year HRs for node-positive patients for DMFS and OS were 2.24 (95\% CI 1.25-4.00) and 1.83 (95\% CI 1.07-3.11), respectively.

Distant metastases and competing events

Figure 2 demonstrates how competing events that occurred in this cohort in addition to distant metastases are divided over the 70-gene signature low- and high-risk groups. The 70 -gene signature low versus high risk in this cohort was only significant for prediction of distant metastases, as shown in Fig. 1; Table 1.

For the DMFS analyses, locoregional recurrence was considered a competing event, and therefore, follow-up was censored if occurred first, except when the locoregional event took place within 6 months prior to the distant metastasis. Reanalysing the data without including the locoregional events that occur within 6 months before the patient is diagnosed with distant metastases, gives no substantial difference in survival probabilities (data not shown).

\section{Discussion}

This update of the consecutive 295 patient cohort shows that the 70-gene signature is able to accurately differentiate between patients at a low and a high risk of distant metastases up to 25 years after diagnosis. This gene signature was designed to predict the risk of distant metastases in the first 5 years after diagnosis. Previous analyses by 70-gene signature high risk

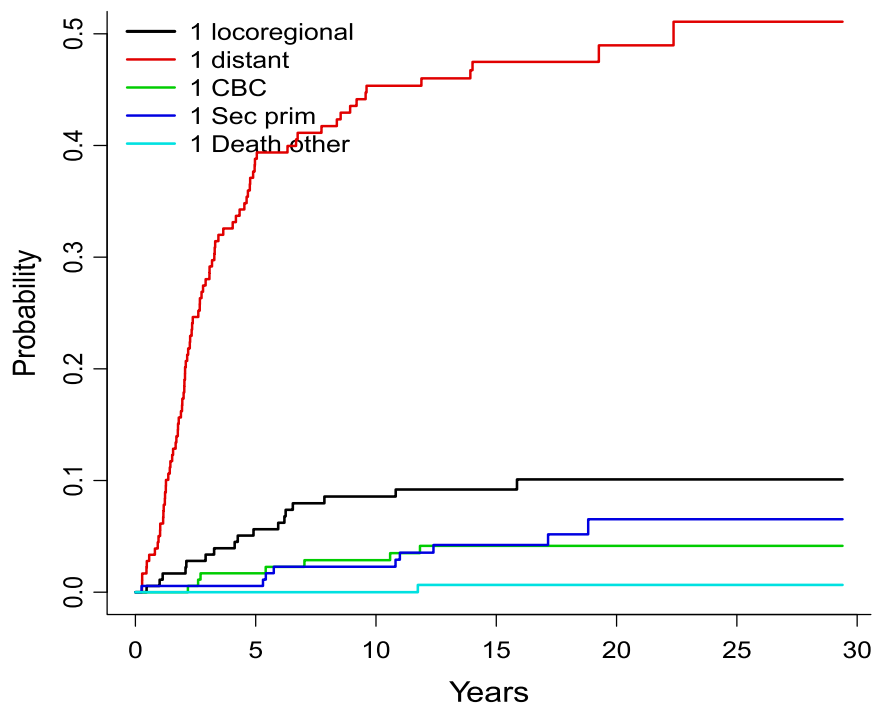

Buyse et al. already confirmed that the 70-gene signature has prognostic value in the first 5 years after diagnosis [3]. Their analyses also suggested that this effect might be present up to 10 years after diagnosis. In our analyses, the 70-gene signature has the largest prognostic value for DMFS and OS in the first 5 years (HRs 9.6 (95\% CI 4.2-22.1) and 11.3 (95\% CI 3.5-36.4) respectively). The significant prognostic value per 5-year intervals for OS remained from 5 years after diagnosis onwards and becomes smaller after 15 years.

Meta-analyses of patients with breast cancer have shown that adjuvant chemotherapy reduces the rate of recurrence almost exclusively in the first 5 years [12]. Consequently, one would expect that patients with relapse in the first 5 years after surgery will benefit most from adjuvant chemotherapy. Thus, for the question of who should receive adjuvant chemotherapy, it is most relevant to identify the patients with relapse in the first 5 years after surgery. That the 70-gene signature has the highest HR for recurrence in the first 5 years supports the notion that this test can help identify those patients that are most likely to benefit from adjuvant chemotherapy. The Food and Drug Administration (FDA) 510-(k) cleared intended use of the 70-gene signature for prognosis prediction in the node-negative, systemically untreated patient population (IVDMIA k101454). The node-negative subgroup of this consecutive series, of whom over $85 \%$ did not receive adjuvant systemic therapy, most closely represents this population; it is shown here that for node-negative patients, long-term outcome can also be predicted using the 70-gene prognosis signature.

Patients included in this cohort were all diagnosed between 1984 and 1995. Due to improvement in adjuvant 
systemic treatment and the introduction of nation-wide screening programs, which resulted in an increase in earlystage breast cancer and a decrease in breast cancer mortality rates, one could hypothesize that the survival probabilities of this cohort if diagnosed today would be even better than shown here [10]. Also of note, the patients included were all younger than 53 years old, who tend to have a poorer prognosis compared to patients diagnosed at older age [13, 14].

In conclusion, an update of the 70-gene signature consecutive 295 patient cohort shows that the 70-gene signature has long-term prognostic value in patients $<53$ years old with stage I and II breast cancer.

Acknowledgments We acknowledge the efforts of Sjoerd Elias, Stella Mook and Michael Knauer to keep the database used for this study updated. We are indebted to all women who participated in this 70 -gene signature validation study. This work was supported by the EORTC Breast Cancer Group (type 3 Grant 2011/2012), BBMRI-NL, a research infrastructure financed by the Dutch Government (NWO 184.021.007, complementation project 45), and the Dutch Genomics Initiative 'Cancer Genomics Centre'.

Conflict of interest $\mathrm{RB}, \mathrm{MvdV}$ and LvtV are named inventors on the patent for the 70-gene signature used in this study. RB and LvtV report being shareholder in and employed by Agendia NV, the commercial company that markets the 70-gene signature as MammaPrint ${ }^{\mathrm{R}}$.

Open Access This article is distributed under the terms of the Creative Commons Attribution Noncommercial License which permits any noncommercial use, distribution, and reproduction in any medium, provided the original author(s) and the source are credited.

\section{References}

1. van't Veer LJ, Dai H, van de Vijver MJ, He YD, Hart AA, Mao M, Peterse HL, van der Kooy K, Marton MJ, Witteveen AT, Schreiber GJ, Kerkhoven RM, Roberts C, Linsley PS, Bernards R, Friend SH (2002) Gene expression profiling predicts clinical outcome of breast cancer. Nature 415:530-536

2. Bueno-de-Mesquita JM, Linn SC, Keijzer R, Wesseling J, Nuyten DS, van Krimpen C, Meijers C, de Graaf PW, Bos MM, Hart AA, Rutgers EJ, Peterse JL, Halfwerk H, de Groot R, Pronk A, Floore AN, Glas AM, van't Veer LJ, van de Vijver MJ (2009) Validation of 70-gene prognosis signature in node-negative breast cancer. Breast Cancer Res Treat 117:483-495

3. Buyse M, Loi S, van't Veer L, Viale G, Delorenzi M, Glas AM, d'Assignies MS, Bergh J, Lidereau R, Ellis P, Harris A, Bogaerts
J, Therasse P, Floore A, Amakrane M, Piette F, Rutgers E, Sotiriou C, Cardoso F, Piccart MJ (2006) Validation and clinical utility of a 70-gene prognostic signature for women with nodenegative breast cancer. J Natl Cancer Inst 98:1183-1192

4. van de Vijver MJ, He YD, van't Veer LJ, Dai H, Hart AA, Voskuil DW, Schreiber GJ, Peterse JL, Roberts C, Marton MJ, Parrish M, Atsma D, Witteveen A, Glas A, Delahaye L, van der Velde T, Bartelink H, Rodenhuis S, Rutgers ET, Friend SH, Bernards R (2002) A gene-expression signature as a predictor of survival in breast cancer. N Engl J Med 347:1999-2009

5. Knauer M, Cardoso F, Wesseling J, Bedard PL, Linn SC, Rutgers EJ, van't Veer LJ (2010) Identification of a low-risk subgroup of HER-2-positive breast cancer by the 70-gene prognosis signature. Br J Cancer 103:1788-1793

6. Mook S, Schmidt MK, Viale G, Pruneri G, Eekhout I, Floore A, Glas AM, Bogaerts J, Cardoso F, Piccart-Gebhart MJ, Rutgers ET, van't Veer LJ (2009) The 70-gene prognosis-signature predicts disease outcome in breast cancer patients with 1-3 positive lymph nodes in an independent validation study. Breast Cancer Res Treat 116:295-302

7. Mook S, Schmidt MK, Weigelt B, Kreike B, Eekhout I, van de Vijver MJ, Glas AM, Floore A, Rutgers EJ, van't Veer LJ (2010) The 70-gene prognosis signature predicts early metastasis in breast cancer patients between 55 and 70 years of age. Ann Oncol 21:717-722

8. Drukker CA, Bueno-de-Mesquita JM, Retel VP, van Harten WH, van Tinteren H, Wesseling J, Roumen RM, Knauer M, van't Veer LJ, Sonke GS, Rutgers EJ, van de Vijver MJ, Linn SC (2013) A prospective evaluation of a breast cancer prognosis signature in the observational RASTER study. Int J Cancer 133:929-936

9. Paik S, Tang G, Shak S, Kim C, Baker J, Kim W, Cronin M, Baehner FL, Watson D, Bryant J, Costantino JP, Geyer CE Jr, Wickerham DL, Wolmark N (2006) Gene expression and benefit of chemotherapy in women with node-negative, estrogen receptor-positive breast cancer. J Clin Oncol 24:3726-3734

10. Parker JS, Mullins M, Cheang MC, Leung S, Voduc D, Vickery T, Davies S, Fauron C, He X, Hu Z, Quackenbush JF, Stijleman IJ, Palazzo J, Marron JS, Nobel AB, Mardis E, Nielsen TO, Ellis MJ, Perou CM, Bernard PS (2009) Supervised risk predictor of breast cancer based on intrinsic subtypes. J Clin Oncol 27:1160-1167

11. Glas AM, Floore A, Delahaye LJ, Witteveen AT, Pover RC, Bakx N, Lahti-Domenici JS, Bruinsma TJ, Warmoes MO, Bernards R, Wessels LF, van't Veer LJ (2006) Converting a breast cancer microarray signature into a high-throughput diagnostic test. BMC Genomics 7:278

12. Early Breast Cancer Trialists' Collaborative Group (EBCTCG) (2005) Effects of chemotherapy and hormonal therapy for early breast cancer on recurrence and 15-year survival: an overview of the randomised trials. Lancet 365:1687-1717

13. Adami HO, Malker B, Holmberg L, Persson I, Stone B (1986) The relation between survival and age at diagnosis in breast cancer. N Engl J Med 315:559-563

14. Chung M, Chang HR, Bland KI, Wanebo HJ (1996) Younger women with breast carcinoma have a poorer prognosis than older women. Cancer 77:97-103 